\title{
Development of a Semi-Quantitative Food Frequency Questionnaire Based on a Household Nutritional Survey in Communities in North Viet Nam
}

\author{
Dao Van Long ${ }^{1}$, Tran Hieu Hoc ${ }^{2}$, Tran Thanh Do $^{3}$, Dinh Thi Minh ${ }^{4}$ and Ngoan Tran Le ${ }^{5,6 *}$ \\ ${ }^{1}$ Hanoi Medical University Hospital, Hanoi, Viet Nam \\ ${ }^{2}$ Dept. of Surgery, Hanoi Medical University, Hanoi, Viet Nam; \\ ${ }^{3}$ National Institute of Nutrition, Hanoi, Viet Nam; \\ ${ }^{4}$ Saint-Paul General Hospital, Hanoi, Viet Nam \\ ${ }^{5}$ Dept. of Occupational Health, Hanoi Medical University, Viet Nam \\ ${ }^{6}$ Dept. of Public Health, School of Medicine, International University of Health and Welfare, Japan \\ *Corresponding author: Le Tran Ngoan, Department of Occupational Health, Hanoi Medical University, Viet Nam, Dept. of Public \\ Health, School of Medicine, International University of Health and Welfare, Japan, 0000-0001-7862-492X
}

\section{ARTICLE INFO}

Received: 幽 November 30, 2021

Published: January 04, 2022

Citation: Dao Van Long, Tran Hieu Hoc, Tran Thanh Do, Dinh Thi Minh and Le Tran Ngoan. Development of a Semi-Quantitative Food Frequency Questionnaire Based on a Household Nutritional Survey in Communities in North Viet Nam. Biomed J Sci \& Tech Res 40(5)-2022. BJSTR. MS.ID.006501.

Keywords: FFQ; Methodology Dietary Assessment; Nutrition

\section{ABSTRACT}

Background: We conducted a household nutritional survey in communities in North Viet Nam to develop a semi-quantitative food frequency questionnaire (SQFFQ) by the method of 24-hour recall food records in 298 households for three consecutive working days.

Methods: The trained investigators interviewed the household about all food items consumed by themselves at their house during the last 24 hours. We estimated nutrient intake based on the Vietnamese Food Composition Table. We analyzed the percentage contribution of nutrients and stepwise regression analysis to identify food items contributing cumulatively up to about $90 \%$. We also counted frequencies of intake of each of 257 food items consumed by participants to clarify categories in the SQFFQ.

Results: We selected 97 food items that covered over $90 \%$ of 16 interested nutrients. The database comprised of 12 food groups: cereals (9 items), peanuts (7) vegetables (24), fruits (10), fat (3), meats (22), fish (10), eggs (4), milk products (3), snacks (2), fish sauces (2), and alcohol (1). We divided these 97 items into two groups having the estimated frequencies of intake at least 2.2\% (73 items) and below this cutoff level (24 items) for further decision in developing a specific SQFFQ. We proposed to classify into seven categories of frequencies of intake: never or seldom, 6-11 times/year, 1-3 times/ month, 1-2 times/week, 3-4 times/week, 5-6 times/week, and 1-3 times/day.

Conclusion: The data provide further evidence based on community diet custom in designing SQFFQ that a simple and relatively inexpensive questionnaire can provide useful information on dietary intake over an extended period during the last 12 months by study participants. Further validation of the designed SQFFQ is needed.

Abbreviations: SQFFQ: Semi-Quantitative Food Frequency Questionnaire; NCD: Non-Communicable Disease; WHO: the World Health Organization; MU: Measuring Unit 


\section{Introduction}

Viet Nam is located in Southeast Asia and had a population of 96.48 million in 2019, an estimated life expectancy at birth of 76 for both genders (Men 71 and women 80) in 2012 [1]. Noncommunicable disease (NCD) caused 379,000 deaths (men 203,300 and women 175,700 ) or $73 \%$ of 520,000 occurred deaths nationwide. About haft of NCD deaths (54.3\% in men and $46.1 \%$ in women) were under 70-year-old [2]. Non-communicable disease appeared to be the major health challenge to national development in the 21st century in the country. Four types of NCD were cardiovascular diseases, cancers, diabetes, and chronic respiratory diseases and their four main modifiable risk factors were tobacco use, unhealthy diets, physical inactivity, and the harmful use of alcohol. The World Health Organization (WHO) has pointed out in 2014 that unhealthy diets caused about 1.7 million NCD deaths globally in 2009 [3]. An unhealthy diet was to be one of the major risk factors and etiologies for developing NCD [3], including cardiovascular diseases, cancer, diabetes, and other chronic diseases. Specific recommendations for a healthy diet included eating more fruit, vegetables, legumes, nuts, and grains; cutting down on salt, sugar, and fats.

It is also advisable to choose unsaturated fats, instead of saturated fats and elimination of trans-fatty acids in our foods/ recipes. To understand the underlying cause of unhealthy diets related to the development of NCD and to address the benefits of nutrients contributed by fruits, vegetables, legumes, nuts, and grains in the prevention of diseases, dietary research is essential to conduct observational studies to the prevention of cancer and NCD in each country and global. The relation of diet to cancer and NCD has been reported in 1914 as far as we have documents [4]. In addition, later in 1947, the scientist has recommended that dietary history as a tool in dietary research [5]. A dietary history provided by study participants in using a semi-quantitative food frequency questionnaire (SQFFQ) to obtain detailed information on individual long-term dietary intake of foods/recipes and nutrients was one of the best methods of dietary research [6]. To collect the dietary history, investigators will interview participants about the average use of foods during the last year, of each specified food. That is, in the prospective Health Professionals Follow-up Study and the Nurses' Health Study in the U.S. [7-9], participants provided information about frequencies of intake (i.e. never or less than once per month, 1-3 per month; 1 per week, 2-4 per week; 5-6 per week, 1 per day, 2-3 per day, 4-5 per day, and 6+ per day).

In the other study in Japan [10], investigators have to classify into seven categories of frequencies of intake (i.e. never or seldom, 1-3 per month; 1-2 per week, 3-4 per week; 5-6 per week, 1 per day, 2 per day, and $3+$ per day). We assumed that participants have three meals a day (breakfast, lunch, and dinner); the lowest frequency of intake was 24 times per year (average of $1-3$ per month) or $2.2 \%$ of 1,095 (365 days x 3) meals per year. To design an SQFFQ the development of the database and selection of foods/recipes items reflected participants' long-term dietary intake was the primary concern. Investigators have identified foods by nutrient contribution and stepwise multiple regression analyses in developing SQFFQ [6,10-12]. This combined analysis of both nutrient contribution and stepwise multiple regression analyses were just computing work, the selected foods based on these approaches might be included some foods with a low frequency or seldom intake (less than 1-3 times per month). To overcome this limitation we proposed to present frequencies of intake by participants for each selected food item in the database to develop a feasible SQFFQ. We conducted a household nutritional survey in communities of three provinces in North Viet Nam to select foods/recipes in developing a database of SQFFQ in collecting information on individual long-term dietary intake from participants of our prospective cohort and case-control studies in Viet Nam.

\section{Methods}

\section{Conduction of a Cross-Sectional Nutritional Survey}

We conducted a cross-sectional nutritional survey, householdbased using the designed questionnaire of 24-hour recall food records. Study sites were in three communes (clusters) represented three provinces located in the Red Delta River in the North Viet Nam, named Hung Yen, Ha Nam, and Bac Ninh (in proximity to the Hanoi city). Study time was in the 4th quarter of 2017.

\section{The Designed Questionnaire of 24-Hour Recall Food Records}

Part 1, family member registration: We collected information of each family member (Name, age, sex) and registered daily for breakfast (main=1/addition=2); lunch (main=3/addition=4); dinner (main=5/addition=6); and places of intake (at home or outside) [13]. Part 2, collection of 24-hour recall food records: We reported data and information for

i) Food name and recipes including information on food/recipe name, processing, and cooking methods.

ii) Weight before eating included name of measuring unit (MU), number of MU, the weight of one MU (in gram), and wasted proportion parts.

iii) Transfer for the next meal included information of food leftover, raw/ cook, name of measuring unit (MU), number of $\mathrm{MU}$, the weight of one MU (in gram), remain in gram, clean-raw equivalence.

iv) Food coded following the list of available foods/recipes in Viet Nam. The designed 24-hour recall food records included these data and information to address Vietnamese diet customs. 
That is, household members eat together and share dishes for breakfast, lunch, and dinner at home. The interviewers attended the trained course in both class and pilot field practices in households for completeness of registered foods/recipes items and the accuracy of collected data and information presented in the designed questionnaire of 24 hour recall food records.

\section{Conducted 24-hour Recall Food Records}

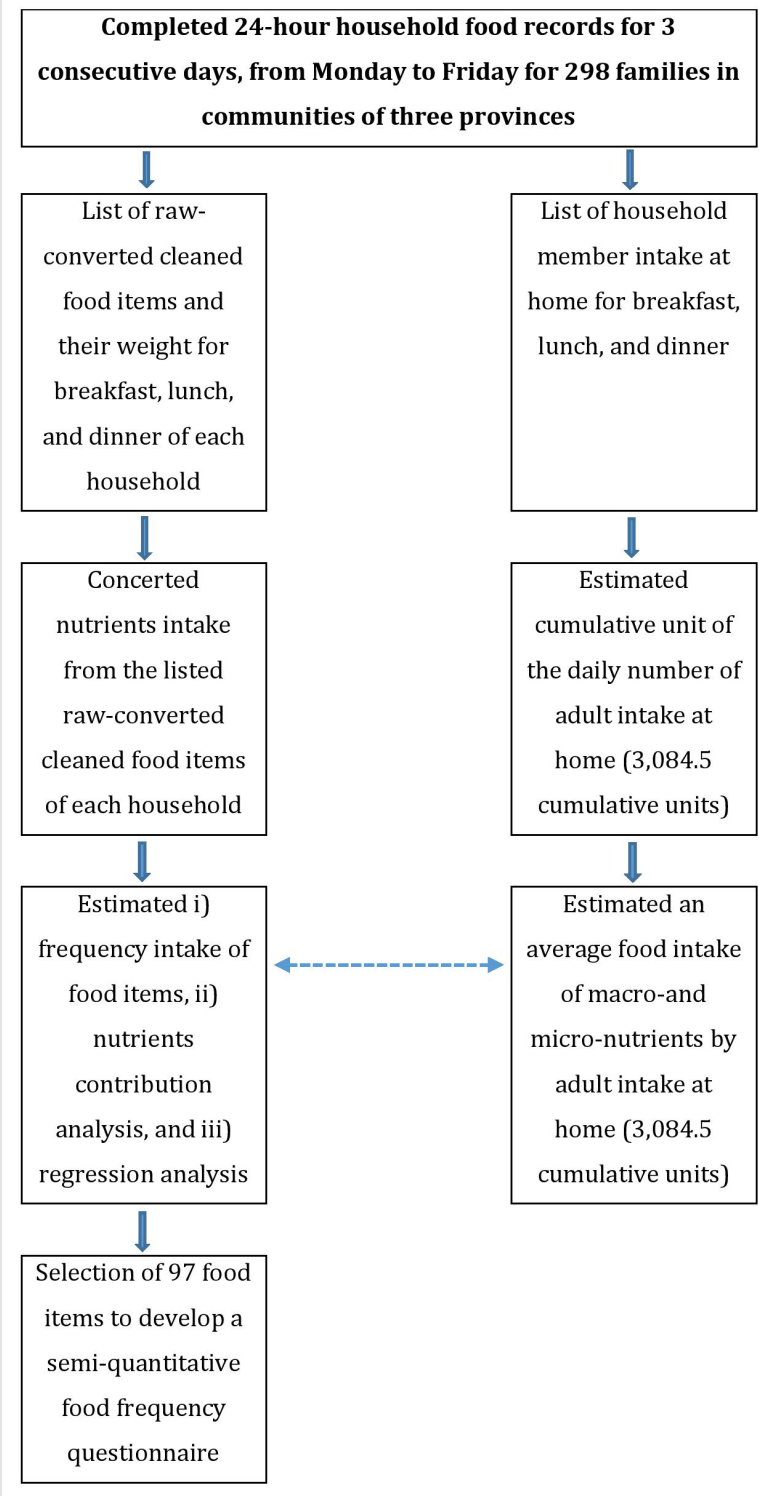

Figure 1: Flow-chart of the household nutritional survey in communities in the North Viet Nam.
A household survey of 24-hour recall food records was conducted in 3 consecutive working days for 300 households (Figure 1) in Hung Yen (100 households), Ha Nam (100 households), and Bac Ninh (100 households) provinces by using the designed questionnaire of 24-hour recall food records from the National Nutrition Institute and its guidelines [13]. We randomly recruited the first household in each cluster, and then recruited the next household based on the door-to-door, until achieved 100 households from each cluster. Finally, we excluded two households in Hung Yen province due to some missing data and errors and there were 298 households to be eligible for the final data analyses in total. Interviews collected dietary information by a face-to-face interview in the households by the two-trained interviewers from the department of Nutrition of Hanoi Medical University. The investigators interviewed the household about all foods/recipes consumed by themselves at their house during the last 24 hours. All household's members were registered for their breakfast (main=1/addition=2); lunch (main=3/addition=4); dinner (main=5/addition=6); places of intake were at home or outside.

The number of family members of 298 households was 1,327 (participated in the first day), 1,321 (second day), and 1,320 (third day). We calculated the number of home rations and weighted by age and sex for each family member, then sum up for total rations daily and three days. We assumed that the intake ratio of food of adult men aged 18-60 was to be 1.0. Then that was 0.4 for the age 1-3, 0.6 for the age 4-6, 0.8 for the age 7-10 and 61 or higher, 1.0 for the age 11-14 (for both boy (men) and girl (women)); 1.2 for boy and 1.1 for the girl for the age group 15-17; and 0.9 for girl (women) age 18-60 [13]. During three consecutive working days, 3,968 person-day were registered and the number of rations was to be 3,084.5 (Figure 1). We reported every food item in each meal with its estimated weight (in gram) and then converted it into a clean-raw weight (in gram). In total, the participated family members of 298 households consumed 257 food items for three days. In three cluster communities, farm markets provided the main foods/recipes as raw products. Before cooking, the clean-raw foods were prepared by excluding the wasted parts. For example, the proportion of wasted parts for some vegetables was $45 \%$ (Maize seeds, fresh, raw), 29\% (Limnophila aromatic), 15\% (Water spinach); and for some fruits was 35\% (Pomelo), 25\% (Orange), and $25 \%$ (Lemon) [14].

We converted into nutrients contributed by all clean-raw food items for every household, for daily, and for three days on average. Nutrients of interest: Based on the Viet Nam Standard 
Food Composition Tables (revision 2007 and updated in 2019) [14], the following 16 nutrients were selected: energy, protein fat, carbohydrate, dietary fiber, vitamins (vitamin A, C, B1, B2, and carotene), minerals (sodium, potassium, magnesium, phosphorus, iron, and zinc). Quality management: when using the designed questionnaire of 24-hour recall food records in the participated households, we used the supported tools included a picture of selected foods/recipes with its portion size and weight of rice, fruits, vegetables, fishes in the condition of raw and cooked foods/ recipes. The experienced research nutritionists have to review and correct any errors for not only of completeness of registered foods but also the accuracy of collected data and information in the completed questionnaire of 24-hour recall food records, and family member registration who shared the foods/recipes at their home.

\section{An Assumption of the Frequency of Intake During the Last Year of Each Specified Food in the Designed SQFFQ}

Based on the prospective Health professionals Follow-up Study and the Nurses' Health Study in the U.S. $[7,8,9,15]$ and the other study in Japan [10], investigators have to classify the lowest frequency of intake as about 24 times per year (average of 1-3 per month). We assumed that participants in our study populations have three meals a day (breakfast, lunch, and dinner); the lowest frequency of intake was 24 times per year (average of 1-3 per month) or $2.2 \%$ of 1,095 (365 days x 3) meals per year. Our study populations comprised 298 households for three days, the total household days were 894. Therefore, we will present results for both select foods/recipes with at least 20 times of intake $(2.2 \%$ of 894), and for foods/recipes with frequencies of intake less than $2.2 \%$ in the database of the current household nutritional survey.

\section{Data analysis and Selection of Foods/Recipes}

We estimated nutrients from the food by multiplying the foods/recipes intake (in grams) with nutrient content per gram of the food as listed in the Vietnamese Food Composition Table [14] (revision 2007 and updated in 2019 (in preparing)) in using an access programming. According to the contribution analysis and multiple regression analysis, we selected all foods/recipes with up to $90 \%$ cumulative contribution for these 16 nutrients. Afterward, all foods/recipes with up to $90 \%$ cumulative contributions and 0.90 cumulative multiple regression co-efficient were included in the SQFFQ. In addition, we estimated frequencies of intake (\%) for each of the foods/recipes against a total of 894 household-day.

\section{Results}

Study participants comprised of 3,968 person-day (1,947 men and 2,021 women). Over $50 \%$ of person-day aged $18-<61$ in both men and women. The aged 61 or older was $11.4 \%$ (men $10.2 \%$ and women 12.6\%). Enfant (Aged 1-<4) included 343 (8.6\% of total person-day), children were 298 (7.5\%) (Aged 4-<7), 269 (6.8\%) (Aged 7-<11), 232 (5.8\%) (Aged 11-<15. The estimated number of rations was 3,084.5, (Table 1). Overall, macronutrients intake by 894 household-day (mean \pm standard deviation (S.D.)) was for energy $(1,878 \pm 432.1 \mathrm{kcal})$, protein $(82.0 \pm 23.5$ grams $)$, animal protein ( $41.2 \pm 21.2$ grams), vegetable oil (12.4 \pm 11.6 grams), fat $(41.7 \pm 22.1$ grams $)$, and carbohydrate $(297.5 \pm 73.2$ grams $)$. The estimated median intake was $1,824.4 \mathrm{kcal}$, a minimum of 826.1 $\mathrm{kcal}$, and a maximum of 3,377.2 kcal. By provinces, the mean energy intake ranked between $1,824.2$ to $1,908.3 \mathrm{kcal}$. The median energy intake ranked between $1,809.2$ to $1,862.6 \mathrm{kcal}$, (Table 2).

Table 1: Characteristics of study participants (in person-day) by age group and gender.

\begin{tabular}{|c|c|c|c|c|c|c|}
\hline \multirow[b]{2}{*}{ Age group* } & \multicolumn{2}{|c|}{ Men } & \multicolumn{2}{|c|}{ Women } & \multicolumn{2}{|c|}{ Men and women combined } \\
\hline & Persons & $\%$ & Persons & $\%$ & Persons & $\%$ \\
\hline $1-<4 \#$ & 193 & 9.9 & 150 & 7.4 & 343 & 8.6 \\
\hline $4-<7$ & 182 & 9.3 & 116 & 5.7 & 298 & 7.5 \\
\hline $7-<11$ & 119 & 6.1 & 150 & 7.4 & 269 & 6.8 \\
\hline $11-<15$ & 110 & 5.6 & 122 & 6.0 & 232 & 5.8 \\
\hline $15-<18$ & 63 & 3.2 & 69 & 3.4 & 132 & 3.3 \\
\hline $18-<61$ & 1,081 & 55.5 & 1,159 & 57.3 & 2,240 & 56.5 \\
\hline $61+$ & 199 & 10.2 & 255 & 12.6 & 454 & 11.4 \\
\hline Total & 1,947 & 100 & 2,021 & 100 & 3,968 & 100 \\
\hline
\end{tabular}

Note: By the age groups, the intake ratio of food of adult men aged 18-60 assumed 1.0. Then that was 0.4 for the age 1-3, 0.6 for the age 4-6, 0.8 for the age 7-10 and 61 or higher, 1.0 for the age 11-14 (for both boy (men) and girl (women)); 1.2 for boy and 1.1 for the girl for the age group 15-17; and 0.9 for girl (women) age 18-60. During three consecutive working days, 3,968 person-day were registered and the number of rations was 3,084.5. \#Children less than 1-year-old not included in the study population because they were not shared foods/recipes with other members in households. 
Table 2: Macronutrients intake by participants in three provinces for one intake ration.

\begin{tabular}{|c|c|c|c|c|c|c|c|c|}
\hline Nutrients & Household day & Mean & S.D. & Minimum & P25 & Median & P75 & Maximum \\
\hline \multicolumn{9}{|c|}{ Ha Nam } \\
\hline Energy (Kcal) & 294 & $1,842.2$ & 378.0 & 905.0 & $1,576.3$ & $1,813.3$ & $2,046.5$ & $3,242.3$ \\
\hline Protein (g) & 294 & 81.3 & 22.8 & 23.7 & 66.0 & 78.9 & 93.4 & 209.3 \\
\hline Animal protein $(\mathrm{g})$ & 294 & 41.5 & 20.7 & 0.0 & 27.8 & 38.9 & 52.1 & 158.1 \\
\hline Vegetables oil (g) & 294 & 12.0 & 12.3 & 1.9 & 3.7 & 7.3 & 16.0 & 79.3 \\
\hline Fat (g) & 294 & 39.8 & 20.5 & 3.9 & 24.5 & 37.3 & 51.8 & 114.6 \\
\hline Carbohydrate (g) & 294 & 294.8 & 65.8 & 155.8 & 252.0 & 293.1 & 329.8 & 549.0 \\
\hline \multicolumn{9}{|c|}{ Hung Yen } \\
\hline Energy (Kcal) & 300 & $1,884.9$ & 478.1 & 826.1 & $1,524.4$ & $1,809.2$ & $2,169.6$ & $3,377.2$ \\
\hline Protein (g) & 300 & 81.8 & 24.9 & 36.0 & 64.0 & 77.5 & 95.4 & 176.0 \\
\hline Animal protein (g) & 300 & 40.3 & 23.2 & 0.8 & 23.9 & 34.8 & 51.4 & 135.4 \\
\hline Vegetables oil (g) & 300 & 12.5 & 11.8 & 1.1 & 4.3 & 9.1 & 15.8 & 76.0 \\
\hline Fat $(\mathrm{g})$ & 300 & 43.4 & 25.5 & 6.3 & 24.5 & 36.9 & 54.5 & 188.4 \\
\hline Carbohydrate (g) & 300 & 293.1 & 80.7 & 82.2 & 239.7 & 284.4 & 342.8 & 600.0 \\
\hline \multicolumn{9}{|c|}{ Bac Ninh } \\
\hline Energy (Kcal) & 300 & $1,908.3$ & 432.3 & 997.3 & $1,612.4$ & $1,862.6$ & $2,149.5$ & $3,176.2$ \\
\hline Protein (g) & 300 & 82.9 & 22.8 & 40.0 & 66.8 & 79.8 & 95.0 & 164.0 \\
\hline Animal protein $(\mathrm{g})$ & 300 & 41.9 & 19.4 & 5.8 & 27.5 & 39.0 & 53.1 & 114.4 \\
\hline Vegetables oil (g) & 300 & 12.8 & 10.8 & 1.6 & 4.8 & 9.2 & 17.9 & 62.7 \\
\hline Fat $(\mathrm{g})$ & 300 & 41.8 & 19.8 & 4.4 & 27.3 & 38.2 & 52.7 & 99.4 \\
\hline Carbohydrate (g) & 300 & 304.6 & 71.8 & 139.8 & 248.2 & 297.2 & 349.9 & 518.9 \\
\hline \multicolumn{9}{|c|}{3 Provinces } \\
\hline Energy (Kcal) & 894 & $1,878.7$ & 432.1 & 826.1 & $1,566.2$ & $1,824.4$ & $2,118.6$ & $3,377.2$ \\
\hline Protein (g) & 894 & 82.0 & 23.5 & 23.7 & 65.7 & 78.8 & 94.8 & 209.3 \\
\hline Animal protein (g) & 894 & 41.2 & 21.2 & 0.0 & 26.8 & 37.8 & 52.1 & 158.1 \\
\hline Vegetables oil (g) & 894 & 12.4 & 11.6 & 1.1 & 4.1 & 8.5 & 16.4 & 79.3 \\
\hline Fat (g) & 894 & 41.7 & 22.1 & 3.9 & 25.1 & 37.4 & 52.8 & 188.4 \\
\hline Carbohydrate (g) & 894 & 297.5 & 73.2 & 82.2 & 247.9 & 293.1 & 342.1 & 600.0 \\
\hline
\end{tabular}

Note: S.D: Standard Deviation, P25: 25th percentile, P75: 75th percentile.

For energy contribution, there were 27 foods/recipes that contributed up to $90 \%$ and the major contribution was ordinary polished rice (58\%), followed by pork medium fat (5\%), wheat noodles (4\%), and pork lean (4\%), (Table 3). The cumulative $\mathrm{R}$ square change was up to 0.91 and included 12 foods/recipes. The highest $\mathrm{R}$ square change was ordinary polished rice (0.75), followed by glutinous rice, milled (0.03), milk, dried-whole powder (0.02), and wheat noodles (0.02), (Table 4). Overall, for 16 nutrients of energy, protein, fat, carbohydrate, dietary fiber, vitamins A, C, B1, B2 and carotene, sodium, potassium, magnesium, phosphorus, iron, and zinc, the number of foods/recipes contributed up to about $90 \%$ was $27,30,24,7,31,13,18,22,38,28,24,33,37,35,38$, and 19 , respectively. For those 16 nutrients, the number of foods/recipes with the cumulative R square up to about $90 \%$ was $12,22,18,2,24$, $5,4,4,17,8,3,20,25,20,27$, and 11, respectively, (Table 5).

Table 3: Energy contribution and cumulative percent contribution up to about $90 \%$.

\begin{tabular}{|c|cl|c|c|}
\hline Food code & \multicolumn{1}{|c|}{ Food name } & Percent contribution & Cumulative percent contribution \\
\hline 1004 & 1 & Ordinary polished rice, raw & $58 \%$ & $58 \%$ \\
\hline 7018 & 2 & Pork medium fat & $5 \%$ & $63 \%$ \\
\hline 1022 & 3 & Wheat noodles, raw & $4 \%$ & $66 \%$ \\
\hline 7017 & 4 & Pork lean & $4 \%$ & $70 \%$ \\
\hline
\end{tabular}




\begin{tabular}{|c|c|c|c|c|}
\hline 3025 & 5 & Soybean curt cake pressed, raw & $2 \%$ & $72 \%$ \\
\hline 1001 & 6 & Glutinous rice, milled, raw & $2 \%$ & $74 \%$ \\
\hline 10006 & 7 & Milk, dried, whole powder & $2 \%$ & $76 \%$ \\
\hline 7013 & 8 & Chicken meat, average & $2 \%$ & $77 \%$ \\
\hline 3017 & 9 & Dried peanut seed & $1 \%$ & $79 \%$ \\
\hline 6011 & 10 & Peanut oil, salad or cooking & $1 \%$ & $80 \%$ \\
\hline 1013 & 11 & Rice noodles, raw & $1 \%$ & $81 \%$ \\
\hline 10001 & 12 & Milk cow, fresh (Fluid) & $1 \%$ & $82 \%$ \\
\hline 9004 & 13 & Duck egg & $1 \%$ & $82 \%$ \\
\hline 4083 & 14 & Water spinach & $1 \%$ & $83 \%$ \\
\hline 9001 & 15 & Hen egg (Raw, whole) & $1 \%$ & $84 \%$ \\
\hline 1020 & 16 & Rice vermicelli, soft noodles & $1 \%$ & $84 \%$ \\
\hline 7028 & 17 & Duck meat, average & $1 \%$ & $85 \%$ \\
\hline 5007 & 18 & Banana, dwarf & $1 \%$ & $86 \%$ \\
\hline 1012 & 19 & Bread, French style & $1 \%$ & $86 \%$ \\
\hline 6004 & 20 & Lard, Liquid & $1 \%$ & $87 \%$ \\
\hline 8032 & 21 & Mrigal carp & $1 \%$ & $87 \%$ \\
\hline 7064 & 22 & Pork, mince fat meat grilled & $1 \%$ & $88 \%$ \\
\hline 7077 & 23 & Pork sausage & $1 \%$ & $88 \%$ \\
\hline 7074 & 24 & Pork floss & $0 \%$ & $88 \%$ \\
\hline 7069 & 25 & Pork, mince lean meat steamed & $0 \%$ & $89 \%$ \\
\hline 14012 & 26 & Local alcohol about 39\%, Vodka & $0 \%$ & $89 \%$ \\
\hline 7032 & 27 & Pork, leg without bone & $0 \%$ & $90 \%$ \\
\hline
\end{tabular}

Table 4: Cumulative R square for energy.

\begin{tabular}{|c|cl|c|c|}
\hline Food code & \multicolumn{1}{|c|}{ Food name } & R square change & Cumulative R square change \\
\hline 1004 & 1 & Ordinary polished rice, raw & 0.75 & 0.75 \\
\hline 1001 & 2 & Glutinous rice, milled, raw & 0.03 & 0.78 \\
\hline 10006 & 3 & Milk, dried, whole powder & 0.02 & 0.80 \\
\hline 1022 & 4 & Wheat noodles, raw & 0.02 & 0.82 \\
\hline 6011 & 5 & Peanut oil, salad, or cooking & 0.02 & 0.84 \\
\hline 1013 & 6 & Rice noodles, raw & 0.01 & 0.85 \\
\hline 14012 & 7 & Local alcohol about 39\%, Vodka & 0.01 & 0.86 \\
\hline 3017 & 8 & Dried peanut seed & 0.01 & 0.87 \\
\hline 7008 & 9 & Dog meat & 0.01 & 0.88 \\
\hline 7018 & 10 & Pork medium fat & 0.01 & 0.89 \\
\hline 1020 & 11 & Rice vermicelli, soft noodles & 0.01 & 0.90 \\
\hline 7017 & 12 & Pork lean & 0.01 & 0.91 \\
\hline
\end{tabular}

Table 5: Number of food contributing with up to $90 \%$ cumulative contribution and 0.90 R square by the participants for each nutrient.

\begin{tabular}{|ll|c|c|c|c|}
\hline & \multicolumn{2}{|c|}{ Contribution analysis } & \multicolumn{2}{c|}{ Regression analysis } \\
\hline \multicolumn{1}{|c|}{ Nutrients } & Number of items & Cumulative Contribution \% & Number of items & Cumulative R square \\
\hline 1 & Energy & 27 & $90 \%$ & 12 & 0.91 \\
\hline 2 & Protein & 30 & $90 \%$ & 22 & 0.90 \\
\hline 3 & Fat & 24 & $90 \%$ & 18 & 0.91 \\
\hline 4 & Carbohydrate & 7 & $90 \%$ & 2 & 0.92 \\
\hline 5 & Fiber & 31 & $90 \%$ & 24 & 0.90 \\
\hline 6 & Vitamin A & 13 & $91 \%$ & 5 & \\
\hline
\end{tabular}




\begin{tabular}{|ll|c|c|c|c|}
\hline 7 & Carotene & 18 & $90 \%$ & 4 & 0.94 \\
\hline 8 & Vitamin B1 & 22 & $90 \%$ & 4 & 0.91 \\
\hline 9 & Vitamin B2 & 38 & $90 \%$ & 9 & 0.90 \\
\hline 10 & Vitamin C & 28 & $90 \%$ & 3 & 0.91 \\
\hline 11 & Sodium & 24 & $90 \%$ & 20 & 0.92 \\
\hline 12 & Potassium & 33 & $90 \%$ & 25 & 0.90 \\
\hline 13 & Magnesium & 37 & $90 \%$ & 20 & 0.90 \\
\hline 14 & Phosphorus & 35 & $90 \%$ & 27 & 0.90 \\
\hline 15 & Iron & 38 & $90 \%$ & & 0.90 \\
\hline 16 & Zinc & 19 & $90 \%$ & & 0.90 \\
\hline
\end{tabular}

In total, 97 foods/recipes were selected and they included 73 items with the frequency of intake of 20 or higher times $2.2 \%$ of 894 household-day) and the remained 24 items with the frequency of intake less than 20 times in total 894 household-day. The highest frequencies of intake were the ordinary polished rice, raw with 891 times $(99.7 \%$ of 894 household-day). The estimated mean intake was 303.4 grams per day, and the percentile (P) was 249.3 grams for P25 and 362.1 grams for P75. The lowest mean intake was one for the beef tongue $(0.1 \%$ of 894 household-day). For detailed selection information of contribution to 16 nutrients of energy, protein, fat, carbohydrate, dietary fiber, vitamins A, C, B1, B2 and carotene, sodium, potassium, magnesium, phosphorus, iron, and zinc by the 97 selected foods/recipes items were presented. Among these 16 nutrients, the highest contribution for 14 nutrients was the milk, dried-whole powder; followed the next contribution for 13 nutrients were 5 items of the ordinary polished rice, raw; water spinach; chicken meat, average; pork lean; and pork medium fat. For detail selection information selection by $\mathrm{R}$ square up to 0.90 cumulative multiple regression co-efficient for 16 nutrients, the ordinary polished rice, raw contributed to 12 , followed by the pork lean to 10, and milk, dried-whole powder, pork medium-fat to 9 nutrients. (Data not shown). In total, the database comprised of 12 groups of foods/recipes that included cereals (9 items), peanuts and beans (7) vegetables (24), fruits (10), fat and oil (3), red and white meats (22), fishes (10), eggs (4), milk and its products (3), snacks (2), salt and fish sauce (2), and alcohol or vodka (1).

\section{Discussion}

\section{The Main Findings}

In total, study participants consumed 257 foods/recipes during three consecutive weekdays by 298 households. The present main findings presented the list of foods/recipes of the database of SQFFQ for dietary research in the country with a unique Vietnamese diet custom in households with the main foods/recipes provided daily from the local farm markets. Based on the nutrient contribution up to $90 \%$ and cumulative R square up to 0.90 multiple regression co-efficient for 16 nutrients, the recommended number of foods/ recipes items was 97 (included 73 items having the frequencies of intake of about $2.2 \%$ or higher and remained 24 items less than $2.2 \%$ of all 894 household-day). We collected from three provinces border with the Hanoi city with a relatively large sample size of 298 households having 1,327 members for three consecutive days that would be currently represented the local nutritional status in developing and designing SQFFQ. We divided 97 selected food items into two groups having the estimated frequencies of intake at least $2.2 \%$ and below this cutoff level for further decision in developing a specific SQFFQ for cancer, other NCD, or focus on a specific nutrient related to consumer's health depended on the local communities. Our results provided the updated nutritional status for the Red Delta River in North Viet Nam for the macronutrients of energy, total protein, total fat, and carbohydrate intake in three communities.

Our innovative approaches were to emphasize developing a database of SQFFQ to study the association of local diet with cancer and other NCD included metabolic disorders and diabetes. Besides, we analyzed and added information on frequencies of intake by 894 household-day in connecting with data computing outcome of cumulative up to $90 \%$ contributions and 0.90 cumulative multiple regression co-efficient $[6,10,11,12]$ for 16 nutrients. Based on the current findings, we proposed the lowest frequency of intake was 6-11 per year for each specific food/recipe. Therefore, we proposed to classify into seven categories of intake frequencies: never or seldom, 6-11 times/year, 1-3 times/month, 1-2 times/week, 3-4 times/week, 5-6 times/week, and 1-3 times/day. The final designed SQFFQ and its validation will report in the other work. Our results of the estimated 16 nutrients of energy, protein, fat, carbohydrate, dietary fiber, vitamins A, C, B1, B2 and carotene, sodium, potassium, magnesium, phosphorus, iron, and zinc have consisted with the findings from the National Nutritional Survey for the same region of the Red Delta River in 2009-2010 [13]. For internal comparison, between three clusters, the estimated amount of intake of these 16 nutrients has also consisted. The results suggested that the present database would be represented the current dietary status of participating communities to develop an SQFFQ. 


\section{Vietnamese Dietary Patterns}

The ordinary polished rice was the main food that contributed up to $58 \%$ of energy with the mean intake per adult person per day of 303.4 grams. The ordinary polished rice is also rich in non-animal protein, vitamin B1, vitamin B5, carbohydrates, and several minerals [14]. The other good diet of Vietnamese is many vegetables, about one-fourth of selected food items (24 of 97 listed items), fruits (10 of 97 listed items), and fish (10 of 97 listed items). The other good diet custom is household-based in using daily fresh farm products. Vietnamese women mainly have meals of breakfast, lunch, and dinner at home and rarely tobacco smoking and alcohol drinking [1,2]. These healthy lifestyles resulted in the positive estimated life expectancy at birth in women was as high as 80 in 2012. In addition, Vietnamese women have the lower estimated cancer incidence rate of all cancers excluding non-melanoma skin cancer $(114.3$ per 100,000 , age-standardized rate using the SegiWorld population structure, ASR) than men 173.0 per 100,000 , ASR), and women in Japan (185.7 per 100,000, ASR), and women in the more developed regions (239.9 per 100,000, ASR) [16]. Using the designed current SQFFQ to clarify protective factors related to foods/recipes against cancer in Viet Nam is timely needed.

\section{Number of Selected Foods/Recipes Included in the SQFFQ}

Our findings suggest that the total listed foods/recipes were 97 items, and the database comprised 12 groups. In other countries in Asia, the number of listed foods/recipes was 102 in Japan [10], 112 in Korea [17], 163 in Singapore [12], 184 in India [18], 119-125 in China $[19,20]$. The number of food items of the present database of SQFFQ in the North Viet Nam (97 items) was shorter than other designed SQFFQ in these countries. To address the quality of our designed SQFFQ, we will report soon the results of its validation of feasibility, practicality, and reliability.

\section{A Possible Limitation of the Present Study}

Our current study was just to select foods/recipes in the development of a database of SQFFQ and it needs to validate. The other limitation was that the obtained foods/recipes have not weighted for each item. Despite these limitations, our findings have the first development of the database of SQFFQ to collect information on individual long-term dietary intake to understand the underlying cause of unhealthy diet-induced cancer and other NCD in the country.

\section{Acknowledgment}

The study was partly supported by Grant Agreement No.: 18/ FIRST/1a/HMU, Under the Project: "Fostering Innovation through Research, Science and Technology".

\section{Conflict of Interest}

There are no conflicts to disclose.

\section{References}

1. (2014) WHO, World Health Organization - Cancer Country Profiles: Viet Nam WHO.

2. (2014) WHO, (Ed.) Global status report on noncommunicable diseases 2014: "Attaining the nine global noncommunicable diseases targets; a shared responsibility", World Health Organization, Geneva.

3. (2009) WHO Global NCD network: a new network to combat noncommunicable diseases, World Health Organization, Geneva.

4. L D Bulkley (1914) The relation of diet to cancer, Medical Record 86: 699-702.

5. B S Burke (1947) The dietary history as a tool in research, Journal of the American Dietetic Association 23: 1041-1046.

6. K Overvad, A Tjonneland, J Haraldsdottir, M Ewertz, O M Jensen, et al. (1991) Development of a semiquantitative food frequency questionnaire to assess food, energy and nutrient intake in Denmark. Int J Epidemiol 20(4): 900-905.

7. D Feskanich, E B Rimm, E L Giovannucci, G A Colditz, M J Stampfer, et al. (1993) Reproducibility and validity of food intake measurements from a semiquantitative food frequency questionnaire. J Am Diet Assoc 93(7): 790-796.

8. E B Rimm, E L Giovannucci, M J Stampfer, G A Colditz, L B Litin, et al (1992) Reproducibility and validity of an expanded self-administered semiquantitative food frequency questionnaire among male health professionals. Am J Epidemiol 135(10): 1114-1126; discussion 1127 1136.

9. W C Willett, L Sampson, M J Stampfer, B Rosner, C Bain, et al. (1985) Reproducibility and validity of a semiquantitative food frequency questionnaire. Am J Epidemiol 122(1): 51-65.

10. S Tokudome, M Ikeda, Y Tokudome, N Imaeda, I Kitagawa, et al (1998) Development of data-based semi-quantitative food frequency questionnaire for dietary studies in middle-aged Japanese. Jpn J Clin Oncol 28(11): 679-687.

11. J Yum, S Lee (2016) Development and evaluation of a dish-based semiquantitative food frequency questionnaire for Korean adolescents. Nutr Res Pract 10(4): 433-441.

12. N Neelakantan, C Whitton, S Seah, H Koh, S A Rebello, et al. (2016) Development of a Semi-Quantitative Food Frequency Questionnaire to Assess the Dietary Intake of a Multi-Ethnic Urban Asian Population. Nutrients 8(9): 528

13. (2010) Ministry of Health, National Institute of Nutrition, National Nutritional Survey, Medical Publishing House, Hanoi city.

14. (2007) Ministry of Health, National Institute of Nutrition, Vietnamese Food Composition Table, Medical Publishing House, Hanoi city.

15. W C Willett, R D Reynolds, S Cottrell-Hoehner, L Sampson, M L Browne, et al. (1987) Validation of a semi-quantitative food frequency questionnaire: comparison with a 1-year diet record. J Am Diet Assoc 87(1): 43-47.

16. (2012) IARC, Globocan 2012: Cancer Incidence, Mortality and Prevalence Worldwide in 2012, IARC (International agency for research on cancer).

17. M K Park, H Y Noh, N Y Song, H Y Paik, S Park, et al. (2012) Validity and reliability of a dish-based, semi-quantitative food frequency questionnaire for Korean diet and cancer research. Asian Pac J Cancer Prev 13(2): 545-552. 
18. L Bowen, A V Bharathi, S Kinra, B Destavola, A Ness, et al. (2012) Development and evaluation of a semi-quantitative food frequency questionnaire for use in urban and rural India. Asia Pac J Clin Nutr 21(3): 355-360.

19. F Y Song, T Toshiro, K Li, P Yu, X K Lin, et al. (2005) Development of a semi-quantitative food frequency questionnaire for middle-aged

ISSN: 2574-1241

DOI: $10.26717 /$ BJSTR.2022.40.006501

Le Tran Ngoan. Biomed J Sci \& Tech Res

(c) (P) This work is licensed under Creative

Submission Link: https://biomedres.us/submit-manuscript.php inhabitants in the Chaoshan area China. World J Gastroenterol 11(6): 4078-4084.

20. Z Y Zhou, T Takezaki, B Q Mo, H M Sun, W C Wang, et al. (2004) Development of a semi-quantitative food frequency questionnaire to determine variation in nutrient intakes between urban and rural areas of Chongqing China. Asia Pac J Clin Nutr 13(3): 273-228.

$\begin{array}{ll}\text { BIOMEDICAL } & \text { Assets of Publishing with us } \\ \text { RESEARCHES } & \text { - Global archiving of articles } \\ & \text { - Immediate, unrestricted online access } \\ & \text { - Rigorous Peer Review Process } \\ & \text { - Authors Retain Copyrights } \\ \end{array}$

